\section{A discussão política sobre aborto no Brasil: uma síntese}

\author{
Maria Isabel Baltar da Rocha*
}

Este trabalho origina-se de uma pesquisa mais abrangente que vem sendo desenvolvida junto ao Núcleo de Estudos de População da Universidade Estadual de Campinas, com apoio do CNPq. O presente texto se detém na questão do aborto no Brasil, procurando analisar importantes aspectos das discussões e decisões políticas nas esferas da sociedade e do Estado; em relação a este último com ênfase no Poder Executivo e no Parlamento.

A idéia orientadora do estudo é a de que a redemocratização do país, em meados dos anos 80, teve peso fundamental para tornar a questão do aborto mais visível, criando condições para ampliação do debate e elaboração de novas normas e políticas públicas, bem como novas decisões no âmbito do Judiciário. No contexto do processo de democratização e do seu desenvolvimento, houve um fortalecimento da sociedade civil, aumentando sua mobilização em busca de direitos de cidadania. Em relação à questão do aborto, acentuou-se a atuação do movimento feminista no sentido de enfrentá-la politicamente no país - movimento social este que é o principal ator comprometido com mudanças de mentalidade e institucionais a respeito do assunto.

O estudo está periodizado em dois momentos da história política recente do Brasil: na etapa do Estado autoritário, de 1964 a 1985, subdividida em duas fases; e na do Estado democrático, a partir de 1985, também com uma subdivisão. Utilizam-se, como fontes de informação, a legislação referente ao tema, documentos do governo - Executivo e Legislativo - e da sociedade civil e materiais da mídia escrita, além da literatura especializada na questão.

Apesar da delimitação desse marco histórico para a preparação do presente texto, é fundamental registrar que as normas legais que são referências para o debate no país foram formuladas nos anos 40 , durante o período ditatorial do Estado Novo. A divulgação e a prática do aborto eram punidas por diferentes instrumentos legais - sendo o principal deles o Código Penal, que ainda hoje considera o aborto um crime (ROCHA e ANDALAFT NETO, 2003).

Nesse código, no capítulo intitulado "Dos Crimes contra a Vida", estão previstos como crime (e definidas penas) o aborto provocado pela gestante ou com seu consentimento (art.124) e o aborto provocado por terceiros - sem consentimento da gestante (art.125) ou com seu consentimento (art.126). Está ainda previsto o aumento das penas nas situações de abortamento induzido por terceiros quando, deste ato, resultar lesão corporal de natureza grave ou morte da gestante (art.127). Por fim, um único dispositivo (art.128) dispõe sobre a não punição da prática do abortamento quando provocado por médico. Nesse caso, nas situações do denominado aborto necessário - se não há outro meio de salvar a vida da gestante - e do aborto de gravidez resultante de estupro.

Ressalte-se que, apesar do teor dessa lei, o Poder Judiciário vem autorizando, em várias ocasiões, desde os anos 90 , o aborto nas situações de anomalia fetal grave, incompatível com a vida extra-uterina (FRIGÉRIO et al., 2001; DINIZ e RIBEIRO, 2003). Existe também, em fase de julgamento, uma ação para que o Supremo Tribunal Federal (STF) considere que não constitui crime de aborto a antecipação do parto realizado por médicos no caso de gestantes de fetos anencéfalos.

\footnotetext{
* Pesquisadora do Núcleo de Estudos de População-Nepo/Unicamp. Professora colaboradora do Programa de Pós-Graduação em Demografia do Instituto de Filosofia e Ciências Humanas - IFCH/Unicamp.
} 


\section{Entre o início da ditadura e o começo da transição democrática - 1964 a 1985}

$\mathrm{Na}$ etapa do governo autoritário, a discussão sobre a questão do aborto é feita a partir do recorte de dois momentos da história política do país. O primeiro abrange o amplo período de 1964 a 1979, passando pelos anos mais rigorosos do regime até o começo da fase de abertura política. O segundo, entre 1979 e 1985, corresponde ao período em que se ampliou gradativamente a abertura política, culminando com o fim do governo militar e o começo da transição democrática. Em cada um desses momentos, a discussão sobre aborto apresentou características diferentes.

No primeiro momento analisado - 1964 a 1979 -, as discussões públicas sobre o assunto eram escassas. Na esfera do Estado, o Executivo chegou a decretar um novo Código Penal em 1969, que acabou não entrando em vigor e teve desdobramentos até 1978: mantinha a incriminação do aborto, com exceção dos dois permissivos do código anterior, mas alterava as punições, introduzia controles do Estado para o aborto permitido por lei e aumentava a pena para a mulher que provocasse o auto-aborto, ou que permitisse que alguém o fizesse, embora a reduzisse na situação da denominada defesa da honra. Refletia, assim, a ausência de um debate democrático sobre o tema.

Quanto à discussão no Legislativo, 13 projetos de lei foram apresentados, porém a maioria voltava-se para a liberação da divulgação dos meios anticoncepcionais na Lei das Contravenções Penais, não estando, portanto, no centro do debate sobre a questão do aborto. Esses projetos confirmavam a vedação de anúncio referente à prática do aborto e atualizavam a multa para essa divulgação. Mesmo assim, quatro projetos dessa época foram pioneiros: um deles em relação à descriminalização do aborto e os outros três acerca da ampliação das possibilidades da prática do abortamento. Dois destes, inclusive, chegaram a ser discutidos e rejeitados nas comissões técnicas.

No âmbito da sociedade civil, a discussão sobre a questão do aborto ainda era restrita, não havendo segmentos da sociedade civil dedicados direta e/ou publicamente a esse tema. As manifestações de integrantes da Igreja Católica em relação ao aborto eram mais defensivas do que propositivas, se tivermos como referência a sua influência no Congresso Nacional. As entidades privadas de planejamento familiar/controle da natalidade não consideravam essa questão como foco central e somente indiretamente se referiam ao assunto - fazia parte da sua argumentação defender a anticoncepção para evitar o "aborto criminoso". Por outro lado, a segunda onda do movimento feminista, nascente em meados dos anos 70 no Brasil - em um contexto de ditadura e tendo como aliados na luta pela democracia segmentos sociais com diferentes ideários morais -, não defendia ainda propostas públicas em relação à questão do aborto, o que ocorreria somente a partir de 1980 (BARSTED, 1992).

No período correspondente à ampliação da abertura política - 1979 a 1985 -, não houve nenhuma medida específica na esfera do Executivo diretamente relacionada ao aborto. É possível perceber, isto sim, na formulação do Programa de Assistência Integral à Saúde da Mulher (Paism), pelo Ministério da Saúde, em 1983, algumas breves referências acerca da questão, encontradas no diagnóstico apresentado sobre a saúde da população feminina no país, em que se constatava a falta de informações a respeito do tema, bem como em seus objetivos programáticos, na forma de "evitar o aborto provocado mediante a prevenção da gravidez indesejada". Embora na equipe formuladora desse documento houvesse a participação de feministas, que em outras circunstâncias políticas priorizariam o assunto, sua elaboração estava grandemente marcada pelo debate sobre planejamento familiar/controle da natalidade no país.

Quanto à discussão do Legislativo, nesse período foram apresentadas sete propostas: cinco voltadas diretamente para a questão do aborto e duas nas quais o tema aparecia vinculado a projetos de lei sobre anticoncepção, na mesma linha dos anteriormente referidos. Nas propostas mais 
diretamente vinculadas à questão do aborto e, especificamente, sobre sua incriminação, havia três projetos de lei: um propondo a descriminalização do aborto e dois a ampliação dos permissivos do artigo 128 desse código - já aparecendo em dois destes, mesmo que indiretamente, a influência do movimento feminista no debate no Congresso Nacional.

No âmbito da sociedade civil, cabe ressaltar que a discussão política sobre a questão já era bem menos restrita, com o movimento feminista autônomo agora também em atuação pública. Eventos e publicações são referidos no artigo de Barsted, sobretudo no Rio de Janeiro e São Paulo. A autora destaca um importante encontro de cunho nacional organizado no Rio por um conjunto de entidades e grupos feministas, em 1983, sobre saúde, sexualidade, contracepção e aborto. A seu ver, foi um marco no debate público da questão, que congregou mais de 300 mulheres, repre-sentando 57 grupos de quase todo o país. Conforme o documento final desse encontro, o aborto era considerado um direito e demandava informações para as muIheres e serviços públicos para atendê-lo já se começava a falar sobre políticas públicas nessa área.

\section{Entre o começo da transição democrática e a democracia de hoje - a partir de 1985}

Nessa etapa, a discussão sobre aborto também é dividida em dois momentos. O primeiro abrange um pequeno período, de 1985 a 1989, que corresponde à importante fase da denominada transição democrática, com o fim da ditadura militar no país. O segundo refere-se à democratização política, em que se aperfeiçoam as instituições, por meio da Assembléia Nacional Constituinte, estabelecendo-se o Estado Democrático de Direito. Nessas duas fases, as discussões e decisões sobre a questão do aborto refletem diferentes momentos políticos e ambas espelham avanços, se comparadas com a etapa do Estado autoritário.

Na fase de 1985 a 1989, iniciou-se uma transformação nas características do Estado brasileiro e intensificou-se a atuação da sociedade civil. Em relação aos direitos das mulheres, estes entraram na agenda política dos poderes Executivo e Legislativo e novos direitos foram assegurados na Constituição de 1988. Nesse contexto, o debate sobre aborto começou a assumir uma nova dimensão e, inclusive, a refletir enfrentamentos mais acentuados entre as feministas e as entidades religiosas, sobretudo a hierarquia da Igreja Católica.

Com o fim da ditadura militar, em 1985, as mulheres ampliaram sua luta para ocupar espaços políticos na esfera do Executivo e, nesse cenário, foi criado o Conselho Nacional dos Direitos da Mulher (CNDM). Logo em seu início, esse exerceu um importante papel mobilizador dos movimentos de mulheres, inclusive do movimento feminista, em relação à Assembléia Nacional Constituinte - durante sua preparação, em 1986, e no processo constituinte, em 1987 e 1988. Nesse quadro, destaca-se a Carta das Mulheres, documento dirigido aos constituintes, contendo princípios e reivindicações, entre eles o direito à interrupção da gravidez (questão acordada no processo constituinte para não ser submetida àquela Assembléia). Em tal processo foram também incorporadas resoluções da 1 a Conferência Nacional de Saúde e Direitos da Mulher, chamada pelo Ministério da Saúde e realizada em 1986 (ROCHA, 1993).

Quanto ao debate no Legislativo, a discussão sobre a questão do aborto entrou na Constituinte pelas mãos da Igreja Católica, para proibi-lo em todas as circunstâncias e, em grande parte, recebeu apoio de parlamentares evangélicos. O tema gerou um intenso debate em diversos momentos daquele processo, mas acabou não sendo contemplado na nova Carta - exatamente devido à sua característica controversa. Ainda em relação ao debate no Legislativo, agora quanto às suas atividades ordinárias, foram apresentados quatro projetos - dois em 1986 e dois em 1988 - que detinham uma visão restritiva em relação ao aborto. Dois deles apontam para o início de uma reação conservadora à discussão sobre aborto na sociedade $\mathrm{e}$ mesmo no Congresso, neste caso reagindo 
aos dois projetos de lei mais liberais, referidos na etapa anterior.

No âmbito da sociedade civil, essa fase foi fortemente marcada pela preparação da Constituinte e, sobretudo, pelo seu próprio processo. Os dois principais atores políticos e sociais envolvidos na discussão da questão do aborto - o movimento feminista e a Igreja Católica - não somente se prepararam, como também atuaram, direta ou indiretamente, em todas as etapas da Constituinte sobre este e outros assuntos de suas agendas políticas. As mulheres organizadas tiveram essa atuação articulada pelo CNDM e com a participação do movimento autônomo, enquanto a Igreja Católica preparou-se por meio da Conferência Nacional dos Bispos do Brasil. Durante sua 24a Assembléia Geral, também em 1986, essa entidade apresentou o documento denominado "Por uma nova ordem constitucional". No item sobre promoção e defesa da vida, registra-se que esta deve ser preservada desde o primeiro instante da concepção, sendo inaceitável o aborto provocado (ROCHA, 1993).

Já a partir de 1989, iniciou-se uma nova fase na configuração do Estado e da sociedade no Brasil. A Constituição de 1988 abriu as portas para um conjunto de transformações a serem realizadas a partir da atuação do Executivo, do Legislativo e do Judiciário, e a sociedade civil passou a ter importantes instrumentos de controle social, ou seja, de controle da sociedade sobre o Estado. A experiência da democracia acabou por trazer algumas significativas mudanças na feição das discussões e decisões sobre os direitos das mulheres e, nesse quadro, sobre a questão do aborto - intensificando-se amplamente esse debate. Antes de elencar relevantes decisões e medidas nesse campo, é interessante ressaltar que parte da discussão que se desenvolveu nesse período, sobretudo a partir de 1993, teve como importante referência a participação do Brasil na Conferência Internacional de População e Desenvolvimento, realizada no Cairo, em 1994, e na Conferência Mundial sobre a Mulher, realizada em Pequim, em 1995.
Na esfera do Executivo, no campo da saúde - agora reestruturado por meio do Sistema Único de Saúde -, é importante referir-se às decisões sobre a questão do aborto no âmbito das Conferências $\mathrm{Na}$ cionais de Saúde, do Conselho Nacional de Saúde e da Área Técnica de Saúde da Mulher, do Ministério correspondente. Para este texto, destaca-se a norma sobre prevenção e tratamento referentes à violência sexual contra a mulher, dessa área técnica, que aplica o artigo 128 do Código Penal sobre o abortamento não punível pela lei -, ampliando medidas originalmente adotadas por alguns governos municipais, estaduais ou universidades, já nos anos 80 . A iniciativa federal datada em dois momentos - o primeiro em 1998 e uma versão atualizada e ampliada em 2005 - teve repercussão na ampliação do número de serviços de saúde que atendem o aborto legal. Estudo de Talib e Citeli (2005) localizou 37 hospitais que realizam ou que estão preparados para realizarem esse atendimento, em 21 Estados e no Distrito Federal.

O tema também esteve presente na IV Conferência Nacional de Direitos Humanos, realizada em 1999, e no plano dela resultante, em 2002, elaborado pela Secretaria de Estado dessa área. Ali se propõe, conforme Ventura (2004, p.43), "o alargamento dos permissivos para a prática do aborto legal, em conformidade com os compromissos assumidos pelo Estado brasileiro, no marco da plataforma de ação de Pequim".

Por fim, o tema esteve significativamente presente na I Conferência Nacional de Políticas para Mulheres, organizada pela Secretaria Especial respectiva e pelo CNDM, em 2004. O plano dela decorrente incluiu a pauta de "Revisar a legislação que trata da interrupção voluntária da gravidez". Essa decisão implicava a criação de uma Comissão Tripartite, formada por representantes do Executivo, do Legislativo e da sociedade civil, para discutir, elaborar e encaminhar uma proposta de revisão dessa legislação ao Congresso Nacional. E assim ocorreu: o anteprojeto, apresentado em fins de 2005, criava uma lei autorizando o aborto até 12 semanas de gestação e ampliando as 
situações, em relação à legislação em vigor, em que o aborto seria permitido.

Quanto ao Legislativo, sua análise nessa fase da redemocratização política mostra a intensificação do debate no Congresso Nacional, bem como a interrelação da discussão nessa Casa com as esferas do Executivo e do Judiciário e, sobretudo, com segmentos da sociedade civil. Nesse contexto, aumentou a participação de atores políticos e sociais em busca de mudanças liberalizantes na legislação, em grande parte inspirados em uma perspectiva feminista, bem como se ampliou a reação contrária, de conservação ou, mesmo, de retrocesso em relação à lei, quase sempre fundamentada em valores de natureza religiosa.

Imediatamente após a Constituinte, foram apresentados seis projetos de lei, sendo a maioria com o objetivo de ampliar os permissivos legais ou mesmo descriminalizar o aborto. Nas duas legislaturas seguintes, situadas nos anos 90, mais 23 propostas foram apresentadas e sua maior parte era, de algum modo, favorável à permissão da prática do aborto - embora já tivesse começado uma reação a essa tendência no Congresso. Nas duas outras legislaturas posteriores, iniciadas em 1999 e 2003, respectivamente, foram enviadas outras 34 proposições e acentuou-se a reação conservadora, que, na realidade, já vinha emergindo na segunda metade do período anterior. É verdade que houve um breve hiato, em relação a essa manifestação, em que foram apresentados projetos de lei sobre a questão do aborto por malformação fetal. Mas aquela tendência voltou a se acentuar, inicialmente, como uma reação à discussão do aborto por anomalia do feto e, depois, diante das atividades da Comissão Tripartite e da apresentação do seu anteprojeto à Câmara - que, aliás, não chegou a ser votado. Ressalta-se que nenhuma proposta substantiva em relação à discussão do tema foi aprovada.

Por fim, no âmbito da sociedade civil, pode-se destacar, nesse amplo período de 1989 a 2006, o maior envolvimento público dos atores políticos e sociais historicamente comprometidos com o tema - o movimento feminista e a Igreja Católica -, sua ampliação com outros atores, o exercício de novas formas de atuação, a preocupação com seus respectivos discursos e a utilização da mídia como um instrumento político. Houve, sem dúvida, uma grande intensificação do debate.

A questão do aborto é pauta do movimento feminista, integrada no seu temário sobre os direitos das mulheres. Nesse sentido, tem sido objeto de atuação no campo da mudança de mentalidade, da modificação da legislação e da aplicação das políticas públicas, além do trabalho com a imprensa. A questão do aborto é também pauta da Igreja Católica, como parte de sua agenda voltada para a religião e família. Sua postura na discussão política tem sido sobretudo reativa, posicionando-se contrária às iniciativas lideradas pelo movimento feminista ou em consonância com este referentes ao aborto como um direito - e utilizando sua abrangente estrutura para divulgar idéias e exercer pressões. São diferentes visões de mundo, de relações de gênero, de sexualidade e de reprodução, mais uma vez observadas no recente episódio sobre a proposta de descriminalização e legalização do aborto apresentada em 2005. Ambos os atores têm angariado apoio e constituído parcerias. Algumas dessas parcerias são mais freqüentes: em se tratando do movimento feminista, com outros segmentos do movimento de muIheres e com a Federação Brasileira das Sociedades de Ginecologia e Obstetrícia; no que se refere à Igreja Católica, com outras religiões, sobretudo aquelas de denominação evangélica.

Antes de concluir esta síntese, é interessante retornar a questão central do trabalho: será que a redemocratização do Brasil teve um peso importante para tornar visível a questão do aborto, criando condições para ampliação do debate, elaboração de novas normas e políticas públicas, e de novas decisões no âmbito do Judiciário?

De fato, com a redemocratização do país, houve mudanças a respeito da questão do aborto, mas mudanças, sobretudo, na visibilidade do tema, na participação de 
atores políticos e sociais e na ampliação do debate. Não houve modificações significativas na legislação, no entanto conseguiuse estabelecer normas técnicas e criar serviços que procuram garantir o acesso ao aborto previsto em lei e o atendimento das mulheres em situação de abortamento, no âmbito do Poder Executivo. A tensão no Parlamento entre tendências opostas tem, praticamente, paralisado decisões que envolvam mudanças legais: não se avança na legislação, mas também não se retrocede. A via do Judiciário vem sendo trilhada, desde os anos 90 , e existe uma ação em julgamento no STF sobre a interrupção da gestação nos casos de anencefalia do feto.

$\mathrm{Na}$ realidade, com a redemocratização do Brasil, houve um fortalecimento da

\section{Referências bibliográficas}

BARSTED, L.L. Legalização e descriminalização do aborto no Brasil: 10 anos de luta feminista. Revista Estudos Feministas, Rio de Janeiro, n.0, p. 104-30, 1992.

BOBBIO, N. Estado, governo, sociedade: para uma teoria geral da política. Rio de Janeiro: Paz e Terra, 2003.

DINIZ, D.; RIBEIRO, D.C. Aborto por anomalia fetal. Brasília: Letras Livres, 2003.

FRIGÉRIO, M.; SALZO, I.; PIMENTEL, S.; GOLLOP, T.R. Aspectos bioéticos e jurídicos do abortamento no Brasil. Revista da Sociedade Brasileira de Medicina Fetal, São Paulo, v.7, p. 12-18, abril, 2001. sociedade civil, mas muitos dos diretos de cidadania ainda não foram conquistados. Se para melhor qualificar a democracia tivermos como referência a questão da igualdade - como diria Norberto Bobbio (1987), a democracia substancial -, possivelmente encontraremos nas desigualdades de gênero e de classes que há no país uma das principais chaves das ainda restritas mudanças referentes à questão do aborto. Isto é, a democracia formal foi necessária para as mudanças parciais nesse tema, mas não foi suficiente para transformações mais profundas, que deverão estar associadas ao conteúdo dessa democracia, no que diz respeito aos avanços quanto à questão da igualdade nas relações sociais no Brasil.

ROCHA, M.I.B. Política demográfica e Parlamento: debates e decisões sobre o controle da natalidade. Campinas: Nepo/ Unicamp, 1993. (Textos Nepo, 25).

ROCHA, M.I.B.; ANDALAFT NETO, J. A questão do aborto: aspectos clínicos, legislativos e políticos. In: BERQUÓ, E. (Org.). Sexo e vida: panorama da saúde reprodutiva no Brasil. Campinas: Editora da Unicamp, 2003, p. 257-318.

TALIB, R.; CITELI, T. Serviços de aborto legal em hospitais públicos brasileiros. São Paulo: CDD-BR, 2005.

VENTURA, M. Direitos reprodutivos no Brasil. Brasília: FNUAP, 2004.

Recebido para publicação em 11/08/2006. Aceito para publicação em 06/11/2006. 